Article

\title{
Sulfated Chitosan Oligosaccharides Suppress LPS-Induced NO Production via JNK and NF-KB Inactivation
}

\author{
Jung-Hyun Kim ${ }^{1, \dagger}$, Yon-Suk Kim ${ }^{1, \dagger}$, Jin-Woo Hwang ${ }^{1}$, Young-Ki Han ${ }^{1}$, Jung-Suck Lee ${ }^{2}$, \\ Se-Kwon Kim ${ }^{3}$, You-Jin Jeon ${ }^{4}$, Sang-Ho Moon ${ }^{5}$, Byong-Tae Jeon ${ }^{5}$, Young Yil Bahk ${ }^{1, *}$ and \\ Pyo-Jam Park ${ }^{1,5, *}$
}

1 Department of Biotechnology, Konkuk University, Chungju 380-701, Korea

2 Industry-Academic Cooperation Foundation, Jeju National University, Jeju 690-756, Korea

3 Specialized Graduate School \& Technology Convergence, Department of Marine-Bio Convergence Science, Pukyong National University, Busan 608-737, Korea

4 School of Marine Biomedical Sciences, Jeju National University, Jeju 690-756, Korea

5 Korea Nokyong Research Center, Konkuk University, Chungju 380-701, Korea

$\dagger$ These authors contributed equally to this work.

* Authors to whom correspondence should be addressed; E-Mails: byoung1@kku.ac.kr (Y.Y.B.); parkpj@kku.ac.kr (P.-J.P.); Tel.: +82-43-840-3903 (Y.Y.B.); +82-43-840-3588 (P.-J.P.); Fax: +82-43-852-3616 (Y.Y.B. \& P.-J.P.).

External Editor: Derek J. McPhee

Received: 5 August 2014; in revised form: 12 September 2014 / Accepted: 4 November 2014 / Published: 7 November 2014

\begin{abstract}
Various biological effects have been reported for sulfated chitosan oligosaccharides, but the molecular mechanisms of action of their anti-inflammatory effects are still unknown. This study aimed to evaluate the anti-inflammatory effects of sulfated chitosan oligosaccharides and to elucidate the possible mechanisms of action. The results showed that pretreated low molecular weight sulfated chitosan oligosaccharides inhibited the production of nitric oxide (NO) and inflammatory cytokines such as IL- 6 and TNF- $\alpha$ in lipopolysaccharide (LPS)-activated RAW264.7 cells. The sulfated chitosan oligosaccharides also suppressed inducible nitric oxide synthase (iNOS), phosphorylation of JNK and translocation of $\mathrm{p} 65$, a subunit of NF- $\kappa \mathrm{B}$, into the nucleus by inhibiting degradation of I $\kappa \mathrm{B}-\alpha$. Our investigation suggests sulfated chitosan oligosaccharides inhibit IL-6/TNF- $\alpha$ in LPS-induced macrophages, regulated by mitogen-activated protein kinases (MAPKs) pathways dependent on NF- $\kappa$ B activation.
\end{abstract}


Keywords: sulfated chitosan oligosaccharides; RAW264.7 cells; MAPKs pathways; anti-inflammatory

\section{Introduction}

Chitosan oligosaccharides (COSs) are partially hydrolyzed products of chitosan, a biopolymer composed of $\beta$-(1-4)-linked $N$-acetyl-D-glucosamine and deacetylated glucosamine units [1]. Chitosan oligosaccharides (Figure 1) have been studied for their various biological effects, including anti-oxidative, anti-tumor, anti-microbial, anti-inflammation, and anti-coagulant properties. In addition, these derivatives could show much improved antioxidant activity compared with chitosan because of the diminished effects of the hydrogen bonds [2-5].

Figure 1. Chemical structure of (A) chitin; (B) chitosan; (C) chitooligosaccahrides; (D) sulfated chitosan oligosaccharide.
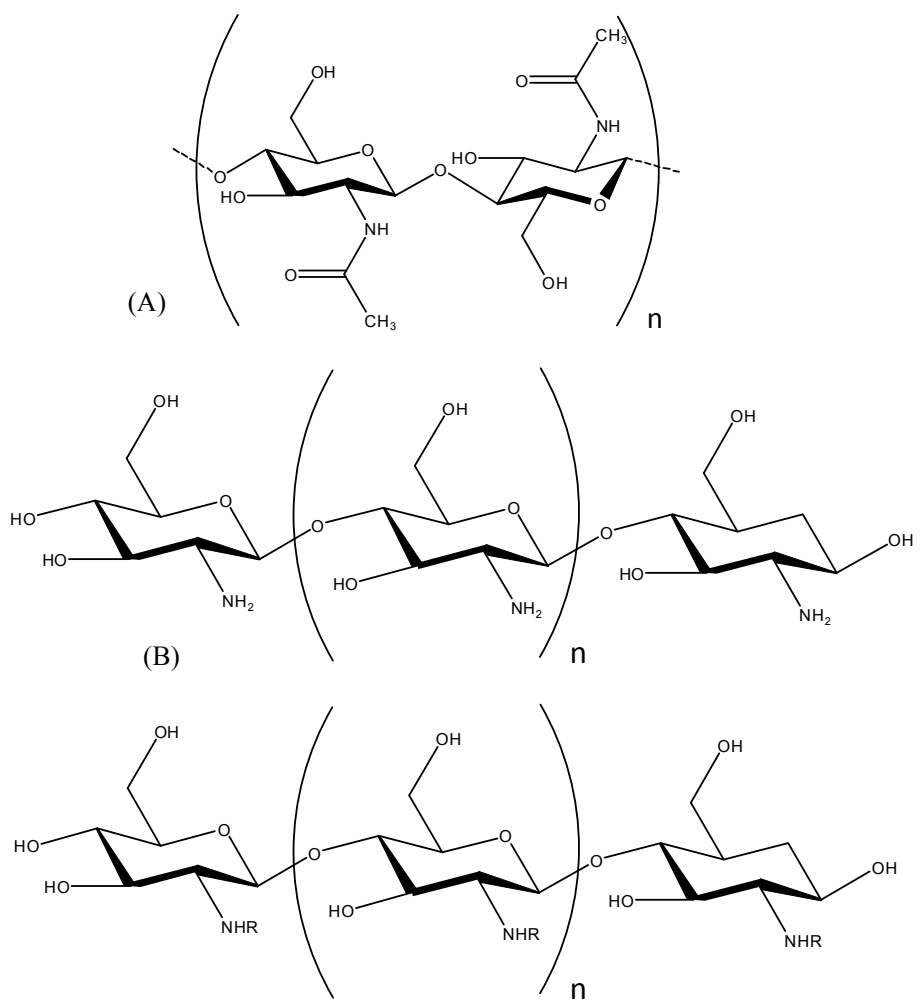

(C)

$\mathrm{R}=\mathrm{H}$ or $\mathrm{Ac}, \mathrm{n}=0$ to 50

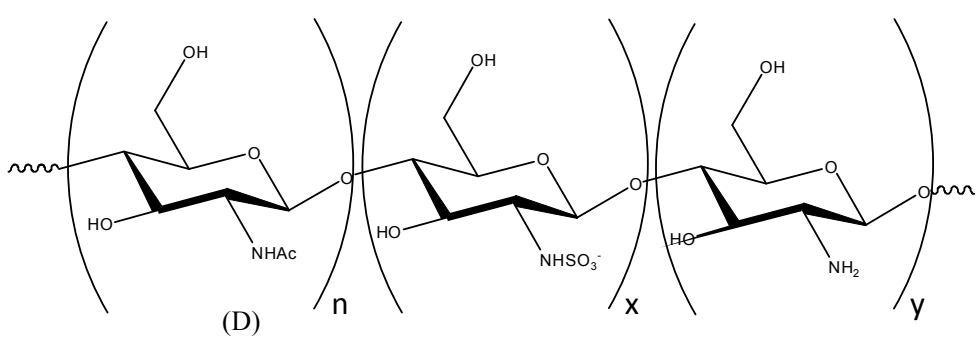

Sulfated polysaccharides display a flexible number of sulfate groups at fixed positions on the molecular backbone, which gives them their characteristic functional properties [6]. However, there 
are no reports on the anti-inflammatory effects of sulfated chitosan oligosaccharides. Hence, this study was undertaken to assess the mechanisms of the anti-inflammatory activity of sulfated chitosan oligosaccharides (S-COSs) in vitro.

Macrophages play important roles in immune responses against various microbial and viral infections by the secretion of nitric oxide (NO) and pro-inflammatory cytokines such as tumor necrosis factor- $\alpha$ (TNF- $\alpha$ ), and interleukin-6 (IL-6) [7,8]. NO, a short-lived free radical, mediates many biological functions such as host defense, neurotransmission, neurotoxicity and vasodilation $[9,10]$. NO is synthesized endogenously by nitric oxide synthases (NOSs) through the conversion of L-arginine to NO and L-citrulline [11,12]. Three type of NOS isoforms were identified; neuronal NOS (nNOS), endothelial NOS (eNOS) and inducible NOS (iNOS). The latter is abundantly expressed and released upon activation by LPS in macrophages and thus simulates different inflammatory diseases including tissue injury and septic shock $[13,14]$. Toll-like receptor 4 (TLR4) is the extra-cellular receptor that recognizes LPS and causes the release of inflammatory mediators via two basic pathways, namely the myeloid differentiation factor-88 (MyD88) pathway and the TIR domain-containing adaptor inducing interferon- $\beta$ (TRIF) pathway.

The MyD88-dependent pathway mediates activation of mitogen-activated protein kinases (MAPKs) such as extracellular signal-related kinase, p38 or c-Jun NH2-terminal kinase (JNK) and PI3K/Akt [15]. These kinases regulate expression of inflammatory genes via activation of downstream NF- $\kappa \mathrm{B}$ by degrading I $\mathrm{KB}-\alpha$ [16]. iNOS expression is essential for the activation of MyD88-dependent and TRIF-dependent signaling pathways in LPS-stimulated macrophages [17].

Based on all this information, in the present study we aimed to investigated the anti-inflammatory potential of sulfated chitosan oligosaccharides (S-COSs) and its molecular mechanism of action, the involvement of the MAPKs signaling pathway was studied, and the role played by nuclear factor- $\mathrm{kB}$ $(\mathrm{NF}-\mathrm{kB})$ was elucidated in LPS-stimulated RAW264.7 macrophage cells.

\section{Results}

\subsection{Preparation of Chitooligosaccharides (COSs) and Sulfated COSs (S-COSs)}

Three kinds of COSs, identified as HMWCOSs, MMWCOSs and LMWCOSs, were successfully prepared from $90 \%$ deacetylated chitosan using an UF membrane reactor system. To improve the biological activity, sulfated chitosan oligosaccharides were prepared according to our previous method [18]. In general, trimethylamine-sulfur trioxide is known to affect selective $N$-sulfation of amino alcohols [19], and it supplements the use of the pyridine- $\mathrm{SO}_{3}$ complex and related reagents with chitosan reported earlier [20,21]. In this study, sulfated COSs such as S-HMWCOSs, S-MMWCOSs and S-LMWCOSs were obtained in over 90\% yields from HMWCOSs, MMWCOSs and LMWCOSs as white, fluffy and water-soluble materials. This synthetic mechanism was substitution by sulfate at the C-2, C-3, and C-6 positions [22]. Characteristic absorptions derived from the sulfo groups in the IR spectrum at 800,1240 , and $1350 \mathrm{~cm}^{-1}$ were assigned to $\mathrm{C}-\mathrm{O}-\mathrm{S}, \mathrm{S}=\mathrm{O}$, and $\mathrm{S}-\mathrm{N}$, respectively [18]. 


\subsection{Effects of Sulfated Chitosan Oligosaccharide (S-COS) Pretreatment on Cell Viability of} LPS-Induced Macrophages

The cytotoxicity of sulfated chitosan oligosaccharides to RAW264.7 cells was measured by MTT assays. RAW264.7 macrophage cells were treated with sulfated chitosan oligosaccharides (S-HMWCOSs, S-MMWCOSs, S-LMWCOSs) at $100 \mu \mathrm{g} / \mathrm{mL}$ for $24 \mathrm{~h}$. As shown in Figure 2A, sulfated chitosan oligosaccharides are not cytotoxic in RAW264.7 cells at concentrations up to $100 \mu \mathrm{g} / \mathrm{mL}$.

Figure 2. Cell viability (A) and nitrite production (B) of sulfated chitosan oligosaccharides (S-HMWCOSs, S-MMWCOSs and S-LMWCOSs) by LPS-stimulated RAW264.7 cells. RAW264.7 cells were treated with sulfated chitosan oligosaccharides (S-HMWCOSs, S-MMWCOSs and S-LMWCOSs) at $100 \mu \mathrm{g} / \mathrm{mL}$ for $24 \mathrm{~h}$. Cell viability was examined by MTT assays. The concentration of NO in the culture medium was determined by using the Griess assay. Results are expressed as mean \pm SEM from three independent experiments. \#\#\# $p<0.001$ versus control, *** $p<0.001$ versus LPS alone group. Dexamethasone (Dexa) used as positive control.
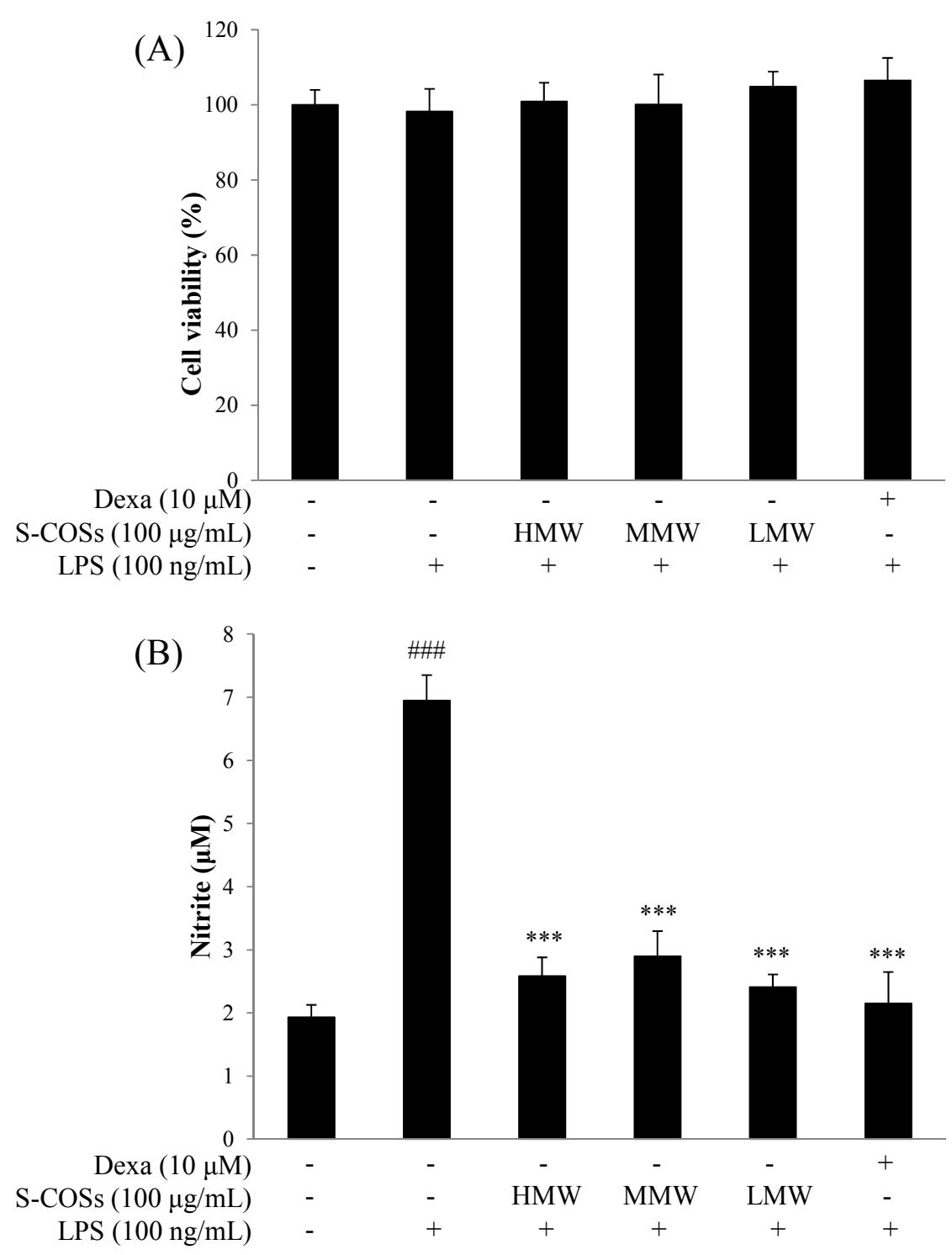


\subsection{Effects of Sulfated Chitosan Oligosaccharides (S-COSs) on LPS-Induced Production of NO in Macrophages}

To investigate whether sulfated chitosan oligosaccharides regulate NO production, RAW264.7 macrophages were incubated with $100 \mathrm{ng} / \mathrm{mL}$ LPS and sulfated chitosan oligosaccharides (S-COSs) for $20 \mathrm{~h}$. In unstimulated RAW 264.7 cells, NO production were almost undetectable, but LPSstimulated cells significantly increased the accumulation of nitrite in the culture medium by approximately 4-fold, and this increase was inhibited by sulfated chitosan oligosaccharides (S-COSs) (Figure 2B). As shown in Figure 2B, the pretreated low molecular weight sulfated chitosan oligosaccharides prepared from 90\% deacetylated chitosan (S-LMWCOSs) showed the most potent NO production reduction in LPS-induced RAW264.7 cells. We then tested the anti-inflammation effects of the S-LMWCOSs with various concentrations $(10,50$ and $100 \mu \mathrm{g} / \mathrm{mL})$ and S-LMWCOSs significantly reduced the level of NO production in LPS-induced RAW264.7 cells in a dose-dependent manner (Figure 3).

Figure 3. Cell viability and nitrite production of sulfated low molecular chitosan oligosaccharides (S-LMWCOSs) in LPS-stimulated RAW264.7 cells. RAW264.7 cells were treated with S-LMWCOSs $(10,50$ and $100 \mu \mathrm{g} / \mathrm{mL})$ in the absence of LPS for $24 \mathrm{~h}$. Cell viability was examined by MTT assays. The concentration of NO in the culture medium was determined by using the Griess assay. Results are expressed as mean \pm SEM from three independent experiments. ${ }^{\# \#} p<0.001$ versus control, *** $p<0.001$ versus LPS alone group. Dexamethasone (Dexa) used as positive control.

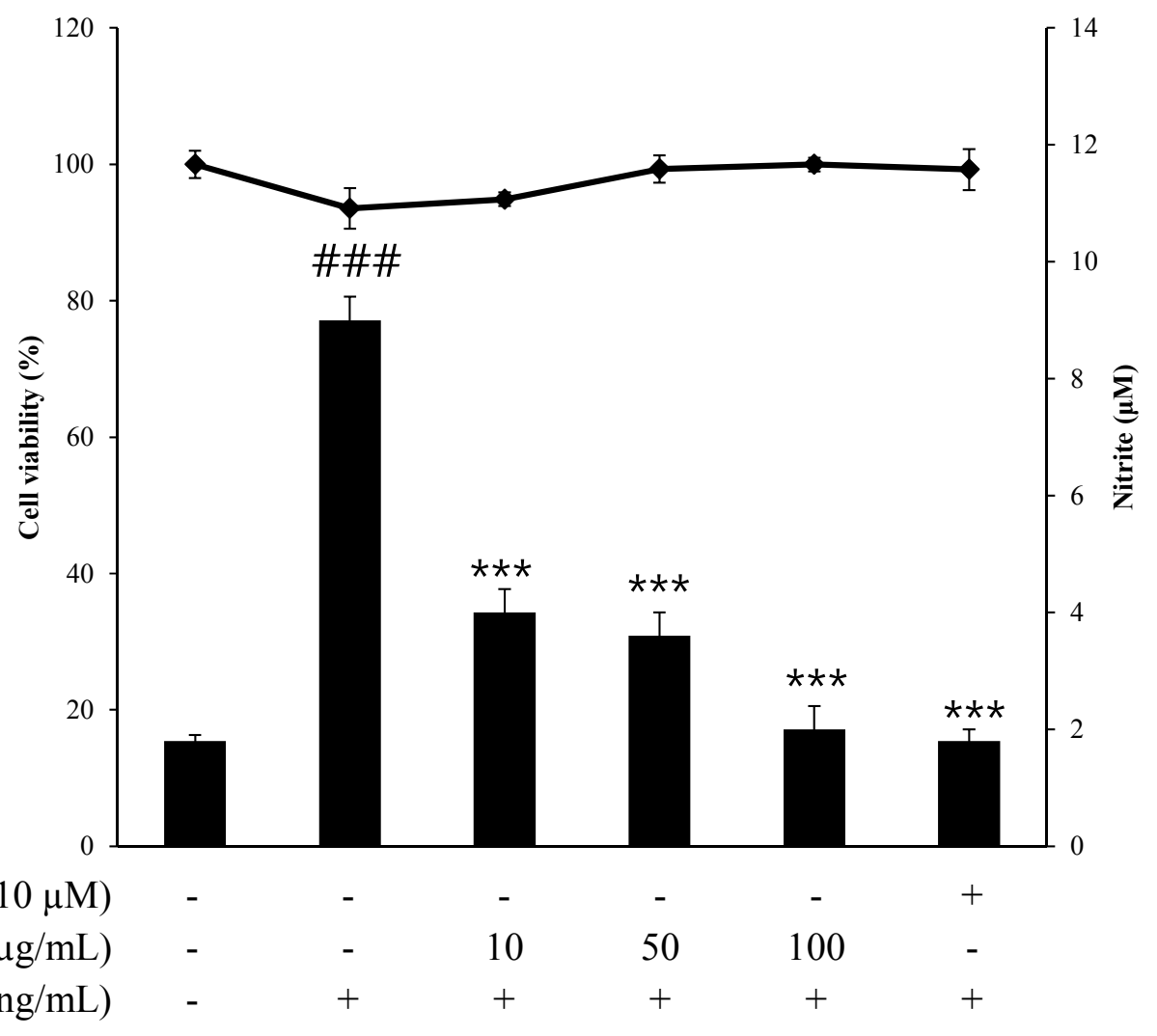




\subsection{Inhibitory Effects of S-LMWCOSs Pretreatment on LPS-Induced ROS in Macrophages}

Reactive oxygen species (ROS), which are synthesized by NADPH oxidase, serve as secondary messengers to activate multiple intracellular proteins and enzymes involved in physiological and pathological states. During inflammation, activated macrophages greatly increase the oxygen uptake resulting in a massive release of ROS called respiratory burst [23]. Overproduction of ROS is thought to be harmful in inflammatory diseases, so we examined the inhibition of ROS production by S-LMWCOSs in LPS-stimulated macrophages. As shown in Figure 4, intracellular ROS production in RAW264.7 cells due to LPS-induced oxidative damage declined when treated with S-LMWCOSs (10, 50 and $100 \mu \mathrm{g} / \mathrm{mL})$.

Figure 4. Inhibitory effects of S-LMWCOSs pretreatment on LPS-induced ROS in macrophages. RAW264.7 cells were incubated with control (A), LPS (B), S-LMWCOSs $10 \mu \mathrm{g} / \mathrm{mL}$ (C), S-LMWCOSs $50 \mu \mathrm{g} / \mathrm{mL}$ (D), S-LMWCOSs $100 \mu \mathrm{g} / \mathrm{mL}$ (E) and Dexamethasone $10 \mu \mathrm{M}$ (F) for $24 \mathrm{~h}$ and quantitation of ROS was analyzed by FACS. The results shown are from one representative experiment repeated twice, with similar results.

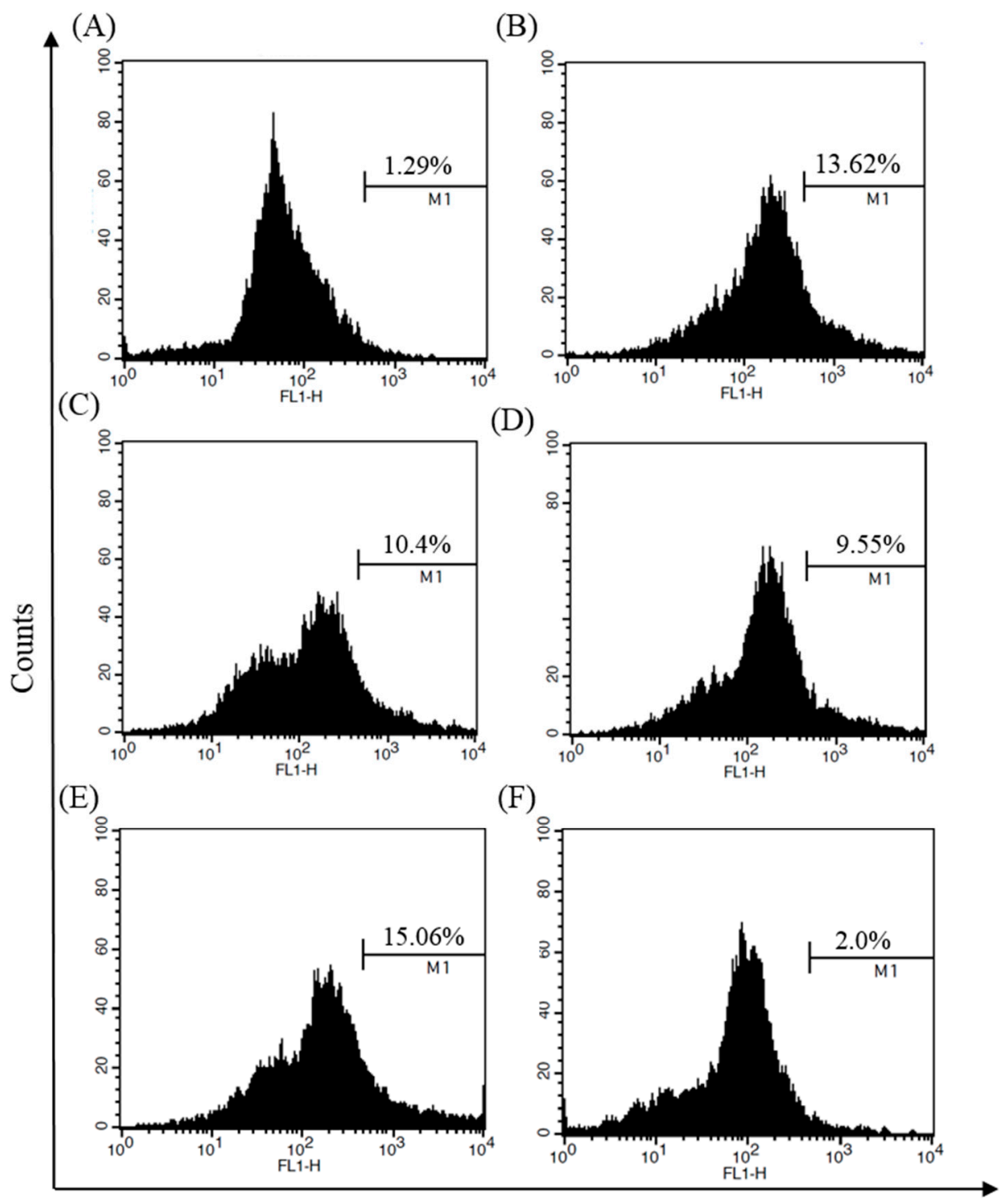

Fluorescence 


\subsection{Inhibitory Effects of S-LMWCOS Pretreatment on LPS-Induced Pro-Inflammatory Cytokines} in Macrophages

To investigate the effects of S-LMWCOSs on proinflammatory cytokine production, ELISA assays were used to measure TNF- $\alpha$ and IL-6 levels in culture media of RAW264.7 cells pretreated with or without S-LMWCOSs $(10,50$ and $100 \mu \mathrm{g} / \mathrm{mL})$ and dexamethasone as a positive control for $1 \mathrm{~h}$ and stimulated with LPS for $2 \mathrm{~h}$. Stimulation of RAW264.7 cells with LPS increased the secreted levels of TNF- $\alpha$, and IL-6, which were significantly reduced by S-LMWCOSs in a dose-dependent manner (Figure 5A,B). The IC 50 value of TNF- $\alpha$, and IL-6 is $93.58 \mu \mathrm{g} / \mathrm{mL}, 94.82 \mu \mathrm{g} / \mathrm{mL}$. In this study, we clearly confirmed that S-LMWCOSs dramatically reduced TNF- $\alpha$ and IL-6 in LPS-induced RAW264.7 cells compared to those of LPS-treated only RAW264.7 cells.

Figure 5. The effects of LMWCOS sulfates on pro-inflammatory cytokines by LPS-stimulated RAW264.7 cells. RAW264.7 cells were treated with the indicated doses of S-LMWCOSs $1 \mathrm{~h}$ before LPS treatment $(100 \mathrm{ng} / \mathrm{mL})$. After incubation of $24 \mathrm{~h}$, the supernatants were taken, and the amounts of IL-6 (A) TNF- $\alpha$ (B) were measured by ELISA. Dexamethasone (Dexa) used as positive control. Results are expressed as mean \pm SEM from three independent experiments. ${ }^{\# \#} p<0.001$ versus control, ${ }^{*} p<0.05,{ }^{* * *} p<0.001$ versus LPS alone group.

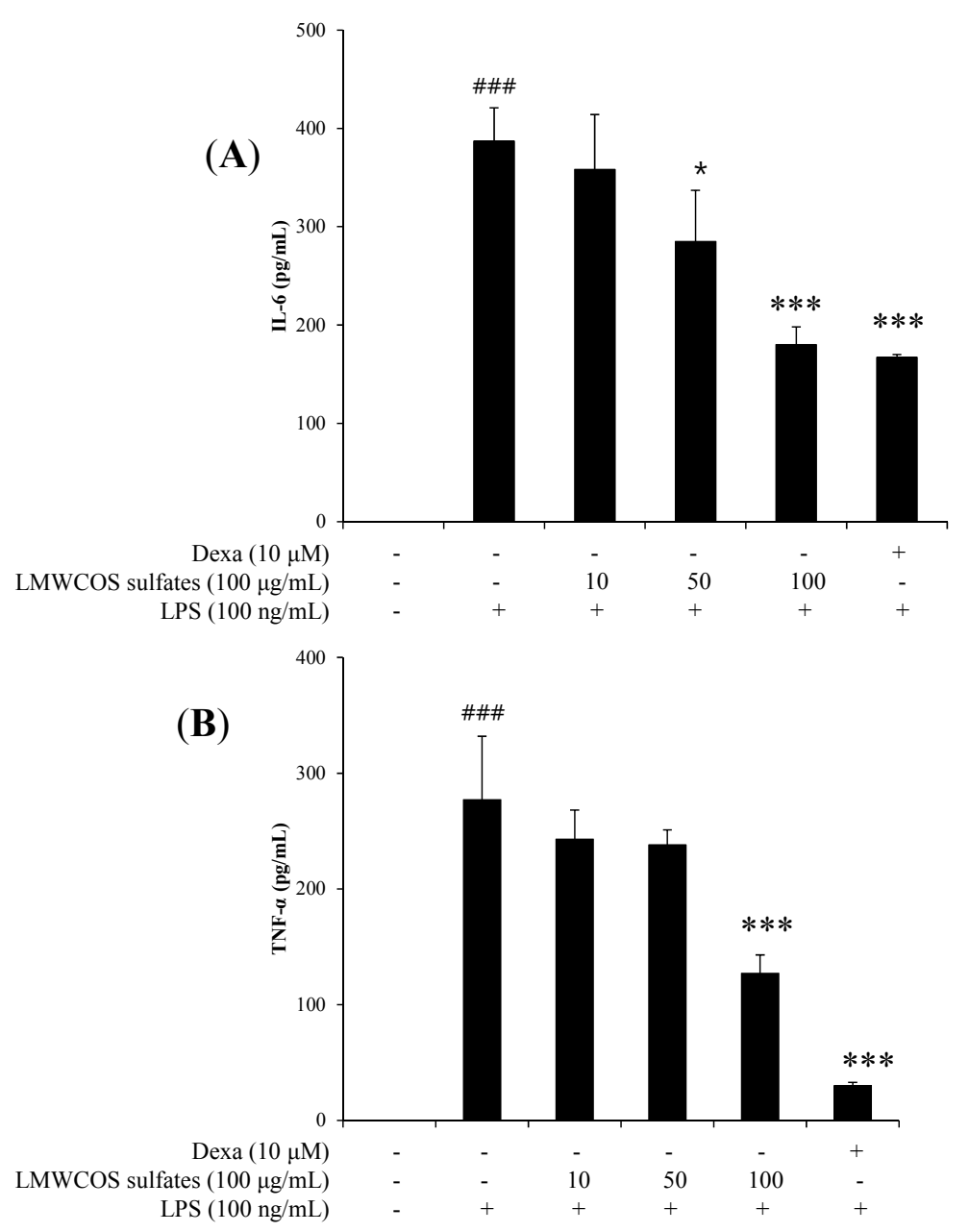




\subsection{Inhibitory Effects of S-LMWCOSs Pretreatment on LPS-Induced iNOS and COX-2} in Macrophages

In order to elucidate the mechanism we investigated the effect of S-LMWCOSs on iNOS and COX-2 protein levels. We observed that various concentrations $(10,50$ and $100 \mu \mathrm{g} / \mathrm{mL})$ of S-LMWCOSs inhibited iNOS expression in the LPS-stimulated RAW264.7 cells (Figure 6). We found that iNOS protein was strongly expressed after stimulation with LPS, and the pre-treatment of S-LMWCOSs markedly decreased the level of iNOS protein in a concentration-dependent manner. As compared to LPS (100\%) the decrease in iNOS for $10 \mu \mathrm{g} / \mathrm{mL}$ was $42 \%$ (60\% NO release), $59 \%$ (78\% NO release) for $50 \mu \mathrm{g} / \mathrm{mL}$ and $74 \%$ (80\% NO release) for $100 \mu \mathrm{g} / \mathrm{mL}$. However we did not observe any significant effect of S-LMWCOSs in LPS-induced COX-2 protein levels.

Figure 6. Effects of S-LMWCOSs on the regulation of various protein expression levels in LPS-stimulated RAW264.7 cells. iNOS, Cox-2, p-ERK, p-JNK, p-p38, IкB- $\alpha$ and actin expression levels were determined by western blotting. Dexamethasone (Dexa) used as positive control. The results shown are from one representative experiment repeated twice, with similar results. ${ }^{\# \# \# ~} p<001$ versus control, $* p<0.05, * * p<0.01, * * * p<0.001$ versus LPS alone group.
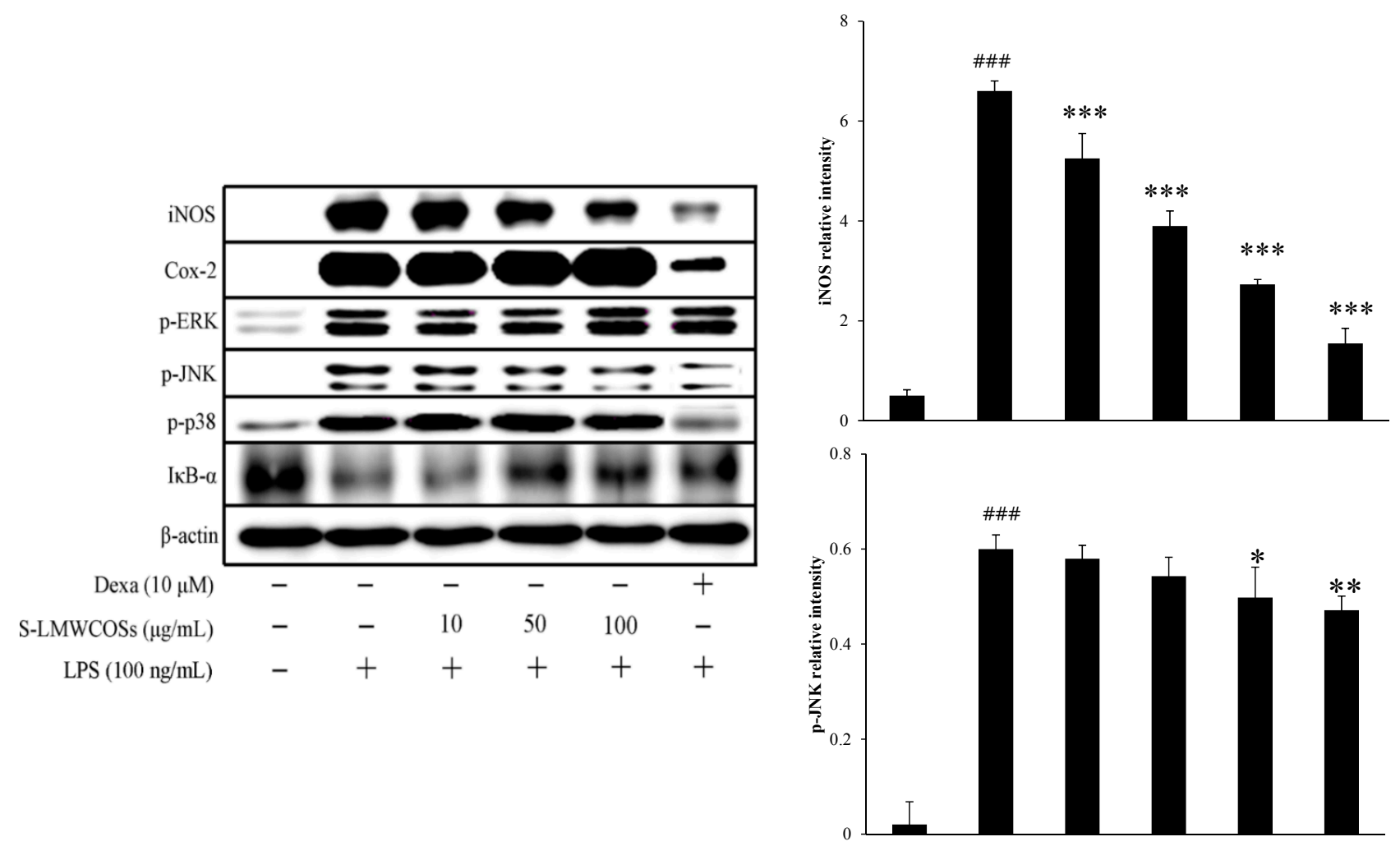

\subsection{Inhibitory Effects of S-LMWCOS Pretreatment on LPS-Induced Phosphorylation of MAP Kinase} and Activation of NF- $\kappa B$ in Macrophages

The MyD88-dependent pathway plays a critical role in the regulation of macrophage activation by activation of mitogen-activated protein kinases (MAPKs). MAPKs including ERK, JNK and p38 also play essential roles in regulation of pro-inflammatory cytokine production. It is known that 
LPS-induced phosphorylation of MAPKs and I $\mathrm{B}-\alpha$ lead to expression of pro-inflammatory mediators in macrophages [24]. To investigate whether the MAPKs pathway was regulated by S-LMWCOSs, we examined the phosphorylation of three MAPKs (ERK, JNK and p38). As shown in Figure 6, S-LMWCOSs decreased LPS-induced phosphorylation of JNK, but didn't affect phosphorylation of p38 and ERK. As a positive control, dexamethasone suppressed the LPS-induced JNK and p38 MAP kinase phosphorylation, without ERK phosphorylation.

$\mathrm{NF}-\kappa \mathrm{B}$ is an important transcription factor in mediating the proinflammatory responses. In

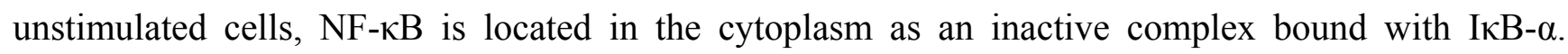

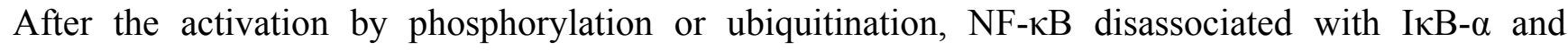
translocate into nucleus to initiate the transcription of target genes [25]. Therefore, we investigated the degradation of IкB- $\alpha$ by western blotting to describe the influence of S-LMWCOSs on LPS-induced NF-kB activation which is consistent with the influence on MAPKs signaling (Figure 6). We observed that phosphorylation of IkB by LMWCOSs $(100 \mu \mathrm{g} / \mathrm{mL})$ was similar to that shown by dexamethasone. Immunofluorescence staining showed that LPS stimulation caused noticeable translocation of NF- $\mathrm{B}$ p65 from the cytoplasm into the nucleus, which was obviously counteracted by S-LMWCOSs pretreatment (Figure 7).

Figure 7. Immunofluorescence staining. The RAW264.7 cells were seeded at the density of $5 \times 10^{4}$ cells/well on the 24 -well plate. Cells were stimulated with LPS $(100 \mathrm{ng} / \mathrm{mL})$ in the absence or presence of S-LMWCOSs $(100 \mu \mathrm{g} / \mathrm{mL})$ added $1 \mathrm{~h}$ before the stimulation. At $30 \mathrm{~min}$ after the LPS addition, sub-cellular location of the NF- $\kappa \mathrm{B}$ p65 subunit was determined by immunofluorescence assay. Cells were treated with the indicated dose of S-LMWCOSs $30 \mathrm{~min}$ before LPS $(100 \mathrm{ng} / \mathrm{mL})$ treatment. The stained cells were visualized using a fluorescence microscope at $200 \times$ magnification.
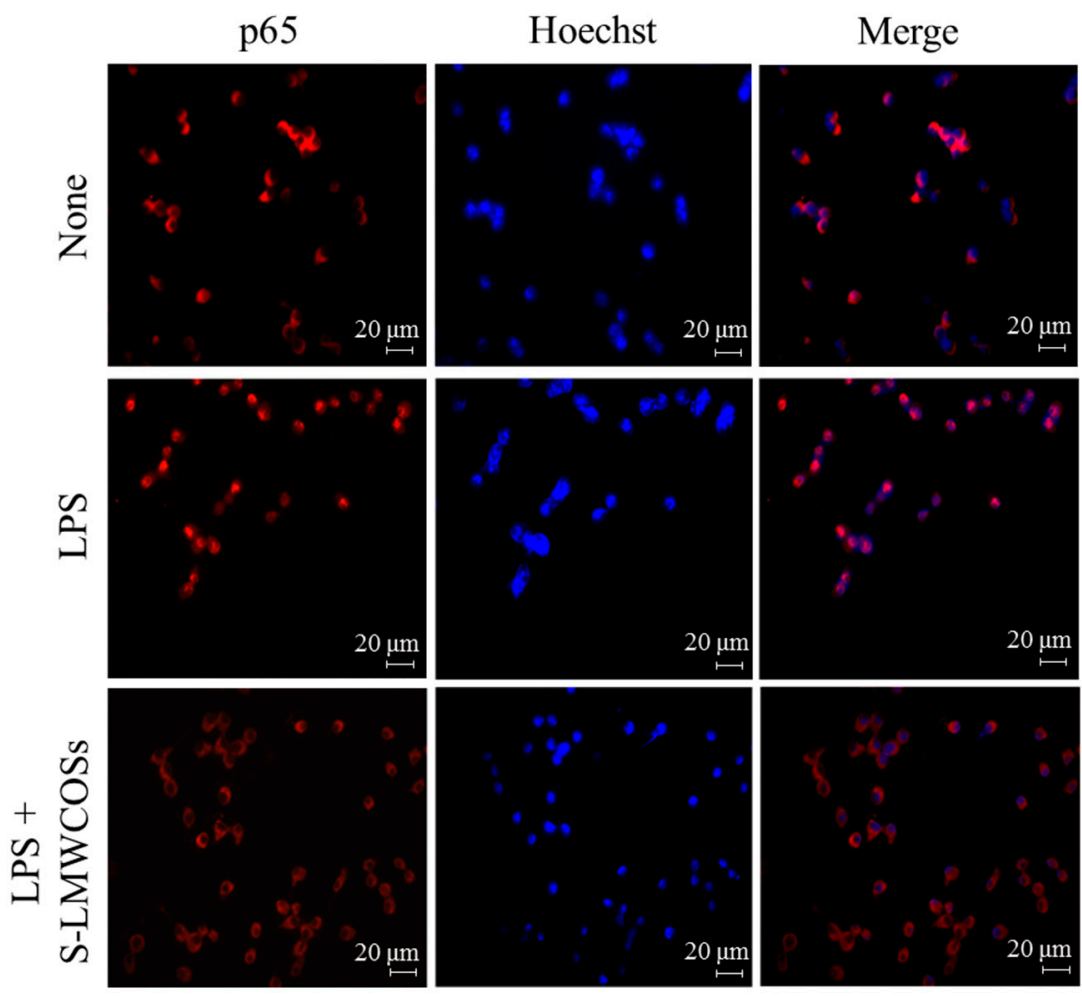


\section{Discussion}

In this study, we examined the potential anti-inflammatory effects of sulfated chitosan oligosaccharides in a LPS-stimulated inflammatory model using RAW264.7 cells and investigated the underlying signaling pathway. Macrophage-derived NO plays important roles in physiology, pathology and inflammatory responses [26]. However, overproduction of NO leads to a variety of diseases such as atherosclerosis, malignancy, rheumatoid arthritis, tissue injuries and septic shock [27,28], therefore, down-regulation of NO is very important for the treatment of these diseases. Before conducting experiments we also confirmed that the selected doses of S-LMWCOSs $(10,50$ and $100 \mu \mathrm{M})$ did not induce cellular toxicity. To explore the mechanism of inhibition of NO production in RAW264.7 macrophages, the effect of sulfated chitosan oligosaccharides on iNOS protein expression was examined. Sulfated low molecular weight chitosan oligosaccharides (S-LMWCOSs) inhibited the expression of iNOS protein in dose-dependent manner.

During the inflammation process, macrophages actively participate in inflammatory responses by releasing the pro-inflammatory cytokines tumor necrosis factor- $\alpha$ (TNF- $\alpha$ ) and IL- 6 , as well as other inflammatory factors, such as NO and prostaglandins (PGs), that recruit additional immune cells to the sites of infection or tissue injury [29]. In this study, we found that S-LMWCOSs dramatically reduced TNF- $\alpha$ and IL-6 in LPS-induced RAW264.7 cells compared to those of LPS-treated only RAW264.7 cells. LPS is known to activate mainly two different signal pathways, the MyD88- dependent (MAPKs and PI3K/Akt) and TRIF-dependent (IFN- $\beta$ /STAT) pathways [30].

The MAPK pathway is one of the important intracellular signaling which cascades in pro-inflammatory responses. MAPKs comprise three subfamilies: p38 MAPK, JNK/stress activated protein kinase and ERK [31,32]. In this study, we found S-LMWCOSs inhibited LPS-induced iNOS in RAW 264.7 macrophages via JNK, but not $\mathrm{p} 38$ MAPK and ERK1/2. Many reports of the differential regulation of MAPKs on LPS-induced NO signaling has been described. Intracellular reactive oxygen species (ROS) have been implicated in the activation of NF-kB in various cell types including macrophages [33]. Recent studies have demonstrated that various natural compounds including ligustilide, resveratrol and curcumin revokes the accumulation of intracellular ROS, suppresses NF-kB activation and inhibits iNOS expression [34,35]. Ligustilide suppressed the LPS-induced production of NO, PGE2 and TNF- $\alpha$ by inhibiting both $\mathrm{IKK} / \mathrm{NF}-\mathrm{kB}$ and MAPK/AP-1 signaling, these effects may be related to the inhibition of LPS-induced intracellular ROS [36].

$\mathrm{NF}-\kappa \mathrm{B}$ is a major factor regulating LPS-induced inflammatory mediators, including iNOS, COX-2, TNF- $\alpha$ and IL- 6 by blocking IкB- $\alpha$ degradation in the cytosol and the nuclear translocation of the NF- $\kappa$ B p65 subunit [37]. Therefore, the suitable regulation of NF- $\kappa$ B may be beneficial in treating many inflammatory disorders.

\section{Experimental Section}

\subsection{Chemicals and Reagents}

90\% Deacetylated chitosan prepared from crab shells was donated by Kitto Life Co. (Pyeongtaek, Korea). The chitosanase (35,000 U/g protein) from Bacillus sp. was purchased from Amicosen Co. (Jinju, Korea), and an ultrafiltration (UF) membrane reactor system (Minitan ${ }^{\mathrm{TM}}$ ) for the production of 
hetero-COSs was from Millipore Co. (Bedford, MA, USA). Dulbecco's modified eagle's medium (DMEM), fetal bovine serum (FBS), penicillin and streptomycin were purchased from Hyclone (Logan, UT, USA). Cell culture wares were purchased from BD Falcon (Franklin lakes, NJ, USA). Antibodies for $\beta$-actin, iNOS and cyclooxygenase (COX)-2 were purchased from Santa Cruz Biotechnology Inc. (Dallas, TEX, USA). Antibodies for phosphorylated-ERK, -p38 and -JNK were purchased from Cell Signaling Technology Inc. (Denver, MA, USA). The detection agents and polyvinylidine fluoride (PVDF) membrane were purchased from Amersham Biosciences (Piscataway, NJ, USA). Lipopolysaccharide (LPS), 2',7-dichlorofluorescein diacetate (DCFH-DA) and 3-(4,5-dimethylthiazol-2-yl)-2,5-diphenyltetrazolium bromide (MTT) were purchased from Sigma Chemical Co. (St. Louis, MO, USA). All other reagents were of the highest grade available commercially.

\subsection{Preparation of Chitooligosaccharides (COSs)}

COSs, which are COSs prepared from 90\% deacetylated chitosan, were prepared by hydrolysis of chitosan in an UF membrane reactor system according to our previous method [18]. Briefly, a 1\% solution of chitosan was prepared by dissolving chitosan $(100 \mathrm{~g})$ in distilled water $(1.0 \mathrm{~L})$ and $1.0 \mathrm{M}$ lactic acid $(550 \mathrm{~mL})$, and the volume was made up to $10.0 \mathrm{~L}$ with distilled water. The $\mathrm{pH}$ was adjusted to 5.5 with a saturated sodium carbonate solution. An UF membrane reactor system was used for the fractionation of COSs. 90\% Deacetylated chitosan was hydrolyzed with an endo-type chitosanase $(35,000 \mathrm{U} / \mathrm{g}$ protein) with a substrate-to-enzyme ratio of $1: 1.5$ units for $36 \mathrm{~h}$ in a batch reactor, and was then heated at $98{ }^{\circ} \mathrm{C}$ for $10 \mathrm{~min}$ to inactivate the enzyme. Thereafter, the hydrolysates were separated using an UF membrane reactor system. The UF membranes used in the system were molecular weight cutoffs (MWCO) 10, 5, and $1 \mathrm{kDa}$, respectively. Chitosan oligosaccharides (COSs) were fractionated into three kinds of COSs with relatively high molecular weights (5000-10,000 Da; HMWCOSs), medium molecular weights (1000-5000 Da; MMWCOSs), and low molecular weights (below $1000 \mathrm{Da}$; LMWCOSs). For detailed information mentioning the molecular weight of COSs please refer the work by Park et al. [18].

\subsection{Preparation of Sulfated Chitooligosaccharides (S-COSs)}

Sulfated chitooligosaccharides (S-COSs) were prepared according to our previous method [18]. COSs (10 g) which had previously been lyophilized were dispersed in distilled water $(1.0 \mathrm{~L})$, and was treated with $2.2 \mathrm{~g}$ sodium carbonate anhydrous and $4.5 \mathrm{~g}$ trimethylamine-sulfur trioxide. The mixture was heated at $65{ }^{\circ} \mathrm{C}$ until a clear viscous solution was obtained for about $12 \mathrm{~h}$. The cooled mixture was then dialyzed exhaustively against distilled water using an electronic dialyzer (Micro Acilyzer G3, Asahi Chemical Industry Co., Tokyo, Japan), and lyophilized. The dialyzer membrane used was Aciplex Cartridge (AC-230-400). Freeze-dried dialyzed samples were obtained as light brown fluffy powders, which were dissolved in distilled water, filtered through $0.2 \mathrm{M}$ filter and used for in vitro experiments. We prepared three kinds of sulfated derivatives (S-HMWCOSs, S-MMWCOSs, S-LMWCOSs) from three kinds of COSs. 


\subsection{Cell Culture}

Murine macrophage RAW264.7 cells from the American Type Culture Collection (ATCC, TIB- $71^{\mathrm{TM}}$ ) were cultured in DMEM medium supplemented with antibiotics (100 units $/ \mathrm{mL}$ of penicillin and $100 \mu \mathrm{g} / \mathrm{mL}$ of streptomycin) and $10 \%$ heat-inactivated FBS and maintained at $37{ }^{\circ} \mathrm{C}$ in a humidified incubator containing $5 \% \mathrm{CO}_{2}$.

\subsection{Determination of Cell Viability Assay}

RAW264.7 cells were plated at a density of $1 \times 10^{4}$ cells/well into 24 -well plates, pre-incubated for $1 \mathrm{~h}$ with three kinds of sulfated chitosan oligosaccharides (S-COSs) at $100 \mu \mathrm{g} / \mathrm{mL}$, various concentrations (10, 50 and $100 \mu \mathrm{g} / \mathrm{mL}$ ) of low molecular weight sulfated chitosan oligosaccharides (S-LMWCOSs) and dexamethasone $(10 \mu \mathrm{M}$, as a positive control), and stimulated with or without $100 \mathrm{ng} / \mathrm{mL}$ of LPS in medium at $37{ }^{\circ} \mathrm{C}$ for $24 \mathrm{~h}$. The cells were subsequently incubated in $500 \mu \mathrm{L}$ of MTT solution $(0.2 \mathrm{mg} / \mathrm{mL})$ at $37{ }^{\circ} \mathrm{C}$ for $4 \mathrm{~h}$. The formazan formed was dissolved in DMSO and measured at a wavelength of $540 \mathrm{~nm}$ using a microplate reader.

\subsection{Determination of Nitric Oxide (NO) Production}

NO concentrations in cultured medium were measured as nitrite by the Griess reagent [38]. RAW264.7 cells were plated at a density of $1 \times 10^{4}$ cells/well into 24 -well plates, pre-incubated with three kinds of sulfated chitosan oligosaccharides (S-COSs), various concentrations (10, 50 and $100 \mu \mathrm{g} / \mathrm{mL})$ of S-LMWCOSs and dexamethasone $(10 \mu \mathrm{M}$, as positive control), and stimulated with $100 \mathrm{ng} / \mathrm{mL}$ of LPS in medium at $37{ }^{\circ} \mathrm{C}$ for $24 \mathrm{~h}$. Each cultured medium (100 $\mu \mathrm{L}$, supernatant) was mixed with $100 \mu \mathrm{L}$ of Griess reagent and incubated at room temperature for $10 \mathrm{~min}$. The absorbance of the mixture was determined at $540 \mathrm{~nm}$ using a microplate reader. All measurements were performed in triplicate. The nitrite levels were determined through a standard curve established with $\mathrm{NaNO}_{2}$.

\subsection{Reactive Oxygen Species (ROS) Assay}

The level of intracellular peroxides was determined by labeling with cell-permeable, 7-dichlorofluorescin diacetate (DCFH-DA) as described previously [39]. Briefly, DCFH-DA (10 $\mu \mathrm{M})$ was added to pre-incubated sulfate chitosan oligosaccharides in RAW264.7 macrophages for $30 \mathrm{~min}$ at $37^{\circ} \mathrm{C}$ in dark, and cells were gently scraped. Fluorescence intensity was analyzed at an excitation wavelength of $485 \mathrm{~nm}$ and an emission wavelength of $535 \mathrm{~nm}$ using a FACS Calibur flow cytometer (Becton \& Dickinson Co., Franklin lakes, NJ, USA).

\subsection{Measurement of Cytokine (IL-6 and TNF- $\alpha$ )}

RAW264.7 cells were plated at a density of $1 \times 10^{4}$ cells/well in 24-well plates, pre-treated with various concentrations $(10,50$ and $100 \mu \mathrm{g} / \mathrm{mL})$ of S-LMWCOSs and dexamethasone $(10 \mu \mathrm{M})$ for $1 \mathrm{~h}$, and stimulated with $100 \mathrm{ng} / \mathrm{mL}$ of LPS in medium at $37{ }^{\circ} \mathrm{C}$ for $2 \mathrm{~h}$ and $18 \mathrm{~h}$. The levels of IL- 6 and TNF- $\alpha$ in cultured medium (supernatant) were measured by enzyme-linked immunosorbent assay 
(ELISA) according to the manufacturer's protocols. The absorbance was determined at $450 \mathrm{~nm}$ using a microplate reader.

\subsection{Western Blot Analysis}

RAW264.7 cells were plated at a density of $2 \times 10^{5}$ cells in $6-\mathrm{cm}$ dish, pre-treated with various concentrations $(10,50$ and $100 \mu \mathrm{g} / \mathrm{mL})$ of S-LMWCOSs and dexamethasone $(10 \mu \mathrm{M})$ for $1 \mathrm{~h}$, and stimulated with LPS $(100 \mathrm{ng} / \mathrm{mL})$. The cells were subsequently washed with PBS, collected, suspended in the lysis buffer ( $150 \mathrm{mM} \mathrm{NaCl}, 10 \mathrm{mM}$ Tris (pH 7.5), $5 \mathrm{mM}$ EDTA, 1\% Triton X-100) containing protease inhibitors $(1 \mu \mathrm{g} / \mathrm{mL}$ leupeptin and $100 \mu \mathrm{g} / \mathrm{mL}$ PMSF) and centrifuged at $12,000 \mathrm{~g}$ at $4{ }^{\circ} \mathrm{C}$ for $20 \mathrm{~min}$ to yield cell lysates. The protein level in each sample was measured using a protein assay kit (Bio-Rad, Laboratories, Inc., Hercules, CA, USA). The proteins (20 $\mu \mathrm{g}$ of RAW264.7 lysates) were separated with 10\% SDS polyacrylamide gels and transferred to polyvinylidene difluoride (PVDF) membranes (GE Healthcare, Little Chalfont, Buckinghamshire, UK). The membranes were then blocked in Tris-buffered saline (TBS)-Tween 20 solution containing 5\% non-fat dry milk and incubated sequentially with primary antibody and horseradish peroxidase-conjugated anti-goat or anti-rabbit IgG (Bio-Rad). The protein bands were then visualized using an ECL detection kit by Luminescent image analyzer (LAS-3000, Fujifilm, Tokyo, Japan).

\subsection{Immunofluorescence Assay}

To determine the intracellular location of the p65 subunit of NF- $\kappa \mathrm{B}$, RAW264.7 cells $\left(1 \times 10^{4}\right.$ cells/well in 24-well plate) were cultured on sterile cover slips in 24-well plates and pretreated with different concentrations of S-LMWCOSs and dexamethasone $(10 \mu \mathrm{M})$ for $1 \mathrm{~h}$. At $30 \mathrm{~min}$ after the LPS treatment, the cells were fixed with methanol for $20 \mathrm{~min}$ at $-20{ }^{\circ} \mathrm{C}$ and washed with PBS for $5 \mathrm{~min}$. The fixed cells were permeabilized with $1 \%$ Triton X-100 in PBS for $1 \mathrm{~h}$ at room temperature, washed three times with PBS for $5 \mathrm{~min}$. The permeabilized cells were then treated with $1 \mathrm{mg} / \mathrm{mL}$ of monoclonal mouse antihuman NF- $\mathrm{BB}$ (p65) for $60 \mathrm{~min}$ at room temperature and then washed with 0.05\% Tween-20 in PBS for 5 min. Cells were then incubated in a 1:2000 dilution of Alexa Fluor 568 - labeled goat anti-mouse antibody for $60 \mathrm{~min}$ at room temperature, washed with PBS for $5 \mathrm{~min}$. Cells were then stained with $0.1 \mu \mathrm{M}$ of Hoechst staining solution for $20 \mathrm{~min}$ at RT and then washed. Finally, the cover slips with cells were dried at RT in an oven for $45 \mathrm{~min}$ and mounted in a 1:1 mixture of xylene and malinol. More than 50 cells per field were counted under a fluorescence microscope.

\subsection{Statistical Analysis}

The data are expressed as mean standard deviation for triplicate determinations. Analysis of variance (ANOVA), accompanied with Tukey's test and Dunnett's test (GraphPad Prism 5), were conducted to identify the significant differences between samples $(p<0.05)$.

\section{Conclusions}

Our findings indicate that low molecular sulfated chitosan oligosaccharides suppressed the pro-inflammatory mediators such as NO and iNOS in LPS-stimulated murine macrophage RAW264.7 
cells. The probable molecular mechanisms behind this bioactivity might be due to inhibition of LPS-induced IL-6 and TNF- $\alpha$ release, by down-regulating the phosphorylation levels of MAPK

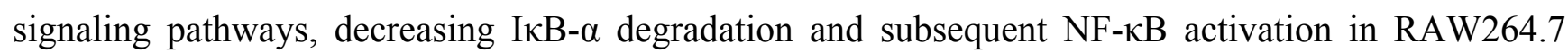
cells. Although the existing data demonstrated an effect of S-LMWCOSs in a cellular model, it would be interesting to reproduce the effect in an animal model of inflammation. Together this data might confirm an anti-inflammatory activity of S-LMWCOSs that might serve as a novel therapeutic for disorders wherein inflammation is one of the pathological features.

\section{Acknowledgments}

This work was supported by a special grant from Konkuk University in 2014.

\section{Author Contributions}

Jung-Hyun Kim: Execution and analysing of experiments, Yon-Suk Kim: Execution of experiments and Manuscript writting, Jin-Woo Hwang, Young-Ki Han, Jung-Suck Lee: Execution of experiments, Se-Kwon Kim, You-Jin Jeon: Preparation of chitooligosaccharides (COSs) and sulfated COSs (S-COSs), Sang-Ho Moon, Byong-Tae Jeon, Young Yil Bahk: Guidance for Planning, execution of experiment and proof reading and manuscript revision, Pyo-Jam Park: Guidance for Planning and execution of experiment

\section{Conflicts of Interest}

The authors declare that there are no conflicts of interest.

\section{References}

1. Fernandes, J.C.; Spindola, H.; de Sousa, V.; Santos-Silva, A.; Pintado, M.E.; Malcata, F.X.; Carvalho, J.E. Anti-Inflammatory Activity of Chitooligosaccharides in Vivo. Mar. Drugs 2010, 8, 1763-1768.

2. Sun, T.; Yao, Q.; Zhou, D.; Mao, F. Antioxidant activity of $N$-carboxymethyl chitosan oligosaccharides. Bioorg. Med. Chem. Lett. 2008, 18, 5774-5776.

3. Sun, T.; Zhou, D.X.; Xie, J.L.; Mao, F. Preparation of chitosan oligomers and their antioxidant activity. Eur. Food Res. Technol. 2007, 225, 451-456.

4. Jung, C.H.; Jung, H.; Shin, Y.C.; Park, J.H.; Jun, C.Y.; Kim, H.M.; Yim, H.S.; Shin, M.G.; Bae, H.S.; Kim, S.H.; et al. Eleutherococcus senticosus extract attenuates LPS-induced iNOS expression through the inhibition of Akt and JNK pathways in murine macrophage. J. Ethnopharmacol. 2007, 113, 183-187.

5. Byun, H.G.; Kim, Y.T.; Park, P.J.; Lin, X.; Kim, S.K. Chitooligosaccharides as a novel $\beta$-secretase inhibitor. Carbohydr. Polym. 2005, 61, 198-202.

6. Wijesinghe, W.A.J.P.; Athukorala, Y.; Jeon, Y.J. Effect of anticoagulative sulfated polysaccharide purified from enzyme-assistant extract of a brown seaweed Ecklonia cava on Wistar rats. Carbohydr. Polym. 2011, 86, 917-921. 
7. Adams, D.O.; Hamilton, T.A. The cell biology of macrophage activation. Annu. Rev. Immunol. 1984, 2, 283-318.

8. Duffield, J.S. The inflammatory macrophage: A story of Jekyll and Hyde. Clin. Sci. 2003, 104, 27-38.

9. MacMicking, J.; Xie, Q.; Nathan, W.C. Nitric oxide and macrophage function. Ann. Rev. Immunol. 1997, 15, 323-350.

10. Moncada, S.; Palmer, R.M.; Higgs, D.A. Nitric oxide: physiology, pathophysiology and pharmacology. Pharmacol. Rev. 1991, 43, 109-142.

11. Hobbs, A.J.; Higgs, A.; Moncada, S. Inhibition of nitric oxide synthase as a potential therapeutic target. Ann. Rev. Pharmacol. Toxicol. 1999, 39, 191-220.

12. Tsai, S.Y.; Chang, Y.; Chen, T.L.; Chen, R.M. Therapeutic concentrations of propofol protects mouse macrophages from nitric oxide-induced cell death and apoptosis. Can. J. Anesth. 2002, 49, 477-480.

13. Chung, H.T.; Pae, H.O.; Choi, B.M.; Billiar, T.R.; Kim, Y.M. Nitric oxide as a bioregulator of apoptosis. Biochem. Biophys. Res. Commun. 2001, 282, 1075-1079.

14. Xie, Q.W.; Cho, H.J.; Calaycay, J.; Mumford, R.A.; Swiderek, K.M.; Lee, T.D. Cloning and characterization of inducible nitric oxide synthase from mouse macrophages. Science 1992, 256, $225-228$.

15. Jeon, Y.J.; Park, P.J.; Kim, S.K. Antimicrobial effect of chitooligosaccharides produced by bioreactor. Carbohydr. Polym. 2001, 44, 71-76.

16. Kawai, T.; Takeuchi, O.; Fujita, T.; Inoue, J.; Muhlradt, P.F.; Sato, S. Lipopolysaccharide stimulates the MyD88-independent pathway and results in activation of IFN-regulatory factor 3 and the expression of a subset of lipopolysaccharide-inducible genes. J. Immunol. 2001, 167, 5887-5894.

17. Ohmori, Y.; Hamilton, T.A. Requirement for STAT1 in LPS-induced gene expression in macrophages. J. Leukoc. Biol. 2001, 69, 598-604.

18. Park, P.J.; Lee, H.K.; Kim, S.K. Preparation of Hetero-Chitooligosaccharides and Their Antimicrobial Activity on Vibrio parahaemolyticus. J. Microbiol. Biotechnol. 2004, 14, 41-47.

19. Warner, D.T.; Coleman, L.L. Selective sulfonation of amino groups in amino alcohols. J. Org. Chem. 1958, 23, 1133-1135.

20. Lloyd, A.G.; Embery, G.; Fowler, L.J. Studies on heparin degradation. I. Preparation of (35S) sulphamate derivatives for studies on heparin degrading enzymes of mammalian origin. Biochem. Pharmacol. 1971, 20, 637-648.

21. Wolfrom, M.L.; Shen Han, T.M. The Sulfation of Chitosan. J. Am. Chem. Soc. 1959, 81, 1764-1766.

22. Vongchan, P.; Sajomasang, W.; Subyen, D.; Kongtawelert, P. Anticoagulant activity of a sulfated chitosan. Carbohydr. Res. 2002, 337, 1239-1242.

23. Aruoma, O.I.; Grootveld, M.; Bahorun, T. Free Radicals in biology and medicine: From inflammation to biotechnology. Biofactors 2006, 27, 1-3.

24. Wang, J.X.; Hou, L.F.; Yang, Y.; Tang, W.; Li, Y.; Zuo, J.P. SM905, an artemisinin derivative, inhibited NO and pro-inflammatory cytokine production by suppressing MAPK and NF- $\mathrm{B}$ pathways in RAW 264.7 macrophages. Acta Pharmacol. Sin. 2009, 10, 1428-1435.

25. Liu, H.T.; Li, W.M.; Huang, P.; Chen, W.J.; Liu, Q.S.; Bai, X.F.; Du, Y.G.; Yu, C. Chitosan oligosaccharides inhibit TNF-induced VCAM-1 and ICAM-1 expression in human umbilical vein endothelial cells by blocking p38 and ERK1/2 signaling pathways. Carbohydr. Polym. 2010, $81,49-56$. 
26. Ghosh, S.; May, M.J.; Kopp, E.B. NF- $\kappa$ B and Rel proteins: Evolutionarily conserved mediators of immune responses. Ann. Rev. Immunol. 1998, 16, 225-260.

27. Nathan, C. Nitric oxide as a secretory product of mammalian cells. FASEB J. 1992, 6, 3051-3064.

28. Detmers, P.A.; Hernandez, M.; Mudgett, M.; Hassing, H.; Burton, C.; Mundt, S. Deficiency in inducible nitric oxide synthase results in reduced atherosclerosis in apolipoprotein E-deficient mice. J. Immunol. 2000, 165, 3430-3435.

29. Bosca, L.; Zeini, M.; Traves, P.G.; Hortelano, S. Nitric oxide and cell viability in inflammatory cells: A role for NO in macrophage function and fate. Toxicology 2005, 208, 249-258.

30. Akira, S.; Takeda, K. Toll-like receptor signaling. Nat. Rev. Immunol. 2004, 4, 499-511.

31. Chen, T.H.; Kao, Y.C.; Chen, B.C.; Chen, C.H.; Chan, P.; Lee, H.M. Dipyridamole activation of mitogen-activated protein kinase phosphatase-1 mediates inhibition of lipopolysaccharide-induced cyclooxygenase-2 expression in RAW 264.7 cells. Eur. J. Pharmacol. 2006, 541, 138-146.

32. Kang, S.R.; Park, K.I.; Park, H.S.; Lee, D.H.; Kim, J.A.; Nagappana, A.; Kim, E.H.; Lee, W.S.; Shin, S.C.; Park, M.K. Anti-inflammatory effect of flavonoids isolated from Korea Citrus aurantium L. on lipopolysaccharide-induced mouse macrophage RAW 264.7 cells by blocking of nuclear factor- $\kappa \mathrm{B}(\mathrm{NF}-\kappa \mathrm{B})$ and mitogen-activated protein kinase (MAPK) signalling pathways. Food Chem. 2011, 129, 1721-1728.

33. Schoonbroodt, S. Piette, Oxidative stress interference with the nuclear factor- $\kappa \mathrm{B}$ activation pathways. J. Biochem. Pharmacol. 2000, 60, 1075-1083.

34. Ben, P.; Liu, J.; Lu, C.; Xu, Y.; Xin, Y.; Fu, J.; Huang, H.; Zhang, Z.; Gao, Y.; Luo, L.; et al. Curcumin promotes degradation of inducible nitric oxide synthase and suppresses its enzyme activity in RAW 264.7 cells. Int. Immunopharmacol. 2011, 11, 179-186.

35. Kwon, O.K.; Lee, M.Y.; Yuk, J.E.; Oh, S.R.; Chin, Y.W.; Lee, H.K.; Ahn, K.S. Anti-inflammatory effects of methanol extracts of the root of Lilium lancifolium on LPS-stimulated Raw264.7 cells. J. Ethnopharmacol. 2010, 130, 28-34.

36. Su, Y.W.; Chiou, W.F.; Chao, S.H.; Lee, M.H.; Chen, C.C.; Tsai, Y.C. Ligustilide prevents LPS-induced iNOS expression in RAW 264.7 macrophages by preventing ROS production and down-regulating the MAPK, NF- $\mathrm{BB}$ and AP-1 signaling pathways. Int. Immunopharmacol. 2011, 11, 1166-1172.

37. Lin, Q.Y.; Jin, L.J.; Cao, Z.H.; Xu, Y.P. Inhibition of inducible nitric oxide synthase by Acanthopanax senticosus extract in RAW264.7 macrophages. J. Ethnopharmacol. 2008, 118 , 231-236.

38. Yoon, W.J.; Ham, Y.M.; Kim, S.S.; Yoo, B.S.; Moon, J.Y.; Baik, J.S.; Lee, N.H.; Hyun, C.G. Suppression of proinflammatory cytokines, iNOS, and COX-2 expression by brown algae Sargassum micracanthum in RAW264.7 macrophages. Eurasian J. BioSci. 2009, 3, 130-143.

39. Bass, D.A.; Parce, W.; Dechatelet, L.R.; Szejda, P.; Seeds, M.C.; Thomas, M. Flow cytometric studies of oxidative product formation by neutrophils: A graded response to membrane stimulation. J. Immunol. 1983, 30, 1910-1917.

Sample Availability: Samples of the compounds are available from the authors.

(C) 2014 by the authors; licensee MDPI, Basel, Switzerland. This article is an open access article distributed under the terms and conditions of the Creative Commons Attribution license (http://creativecommons.org/licenses/by/4.0/). 